\title{
Resultados financeiros: uma análise em empresas do segmento de alimentação fora do domicílio
}

\author{
Financial results: an analysis of the segment of food supply services \\ away from home
}

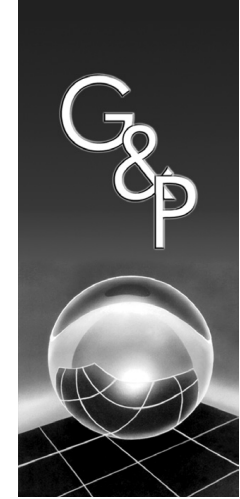

Pedro José Raymundo'

\begin{abstract}
Resumo: O objetivo desta pesquisa é analisar o resultado financeiro das empresas do segmento de alimentação fora do domicílio e divulgar essa análise de forma que possa ser fonte de informação para auxiliar na elaboração do planejamento estratégico-financeiro das empresas do setor. Para tanto, foram definidos os seguintes objetivos específicos: elaborar uma demonstração do resultado do exercício (DRE) por empresa pesquisada; calcular os principais indicadores financeiros dessas empresas como lucratividade, custo da mercadoria vendida (CMV), salário médio, custo de mão de obra, ocupação do imóvel e tributação; verificar a média de consumo por cliente (tíquete médio); identificar a correlação entre os diversos tipos de custos com os resultados financeiros e, por fim, analisar os principais motivos financeiros causadores de resultados negativos entre as empresas que responderam à pesquisa. Quanto aos procedimentos metodológicos, este estudo caracteriza-se como pesquisa descritiva e quantitativa. Os dados foram coletados por meio de questionário eletrônico aplicado em 126 estabelecimentos, situados na cidade de Florianópolis, filiados à Associação Brasileira de Bares e Restaurantes (ABRASEL), no ano de 2013. Em relação aos resultados, a pesquisa alcançou seus objetivos específicos já descritos, com destaque para o percentual de empresas deficitárias (27\%) e correlação negativa entre custos fixos e resultados financeiros. A relevância da pesquisa se dá pelo fato de que ela contribuirá para a divulgação a respeito dos resultados financeiros das empresas do setor e ainda poderá servir para orientar os empreendedores na elaboração do planejamento das empresas do segmento.
\end{abstract}

Palavras-chave: Alimentação fora do domicílio; Custos; Resultados financeiros de restaurantes.

\begin{abstract}
The objective of this research is to analyze the financial results of companies of the away-from-home food supply service segment, and disclose this analysis so that it could be a source of information to assist in the preparation of the strategic and financial planning of such companies. To this end, the following specific objectives were defined: to develop a statement of income and expenditure (SIE) per company surveyed; to calculate the main financial indicators of these companies, such as profitability, cost of goods sold (COGS), average wages, labor costs, real estate occupancy, and taxation; to verify the average consumption per customer (food allowance); to identify the correlation between the various types of costs and financial results; and to analyze the main financial reasons causing negative results among the companies that responded to the survey. Regarding the methodological procedures, the present study is characterized as a descriptive and quantitative research. The data were collected by means of electronic questionnaires applied to 126 commercial establishments located in the municipality of Florianopolis, affiliated to the Brazilian Association of Bars and Restaurants (ABRASEL), in 2013. Concerning the results, the research achieved its previously described specific goals, with emphasis on the percentage of loss-making companies (27\%); minimum correlation between salary level and employee turnover; and strong negative correlation between fixed costs and financial results. This research is important because there is no published information on the financial results of companies of this sector, and it will serve to guide entrepreneurs in the planning of companies from this segment.
\end{abstract}

Keywords: Food away from home; Costs; Financial results for restaurants.

\section{Introdução}

Florianópolis é uma cidade cujo setor de turismo é responsável, de acordo com a Associação Comercial e Industrial de Florianópolis (ACIF, 2013), por cerca de $45 \%$ de seu PIB (Produto Interno Bruto), que somou 9,8 bilhões de reais em 2010, segundo informação do

Instituto Brasileiro de Geografia e Estatística (IBGE, 2013). Assim, este estudo pretende contribuir com o processo de planejamento estratégico voltado para as finanças das empresas de turismo, especialmente dos restaurantes, por se tratar de um tipo muito

\footnotetext{
${ }^{1}$ Instituto Federal de Santa Catarina, Rua Duarte Schutel, 99, CEP 88015-640, Florianópolis, SC, Brasil, e-mail: pedro.raymundo@ifsc.edu.br
}

Recebido em Jul. 15, 2013 - Aceito em Jan. 12, 2015

Suporte financeiro: Nenhum. 
representativo de empresa nesse setor, que, por sua vez, tem um peso considerável na economia local.

Como destaca Cardoso (2011), a maioria das empresas da área de alimentos e bebidas são empreendimentos de pequeno porte, que nem sempre utilizam ferramentas adequadas para gerir os negócios. Diante dessa realidade, cabe destacar a relevância do planejamento e do controle dos custos, o que nem sempre é tratado com a devida importância. Além disso, as questões financeiras fazem parte dos principais motivos que levam as empresas à falência. De acordo com Megliorini (2007), muitas empresas fecham suas portas por falta de lucro ou mesmo em decorrência de lucro que não satisfaz a expectativa do investidor. Estudos do Serviço Brasileiro de Apoio às Micro e Pequenas Empresas (SEBRAE, 2011) também analisam essa realidade. Segundo pesquisa divulgada em 2011, 30\% das empresas constituídas entre os anos de 2005 e 2009 fecharam suas portas antes de completarem dois anos de vida.

Ainda, conforme Megliorini (2007), o empreendedor pode deter a tecnologia necessária para fazer produtos ou prestar serviços com qualidade, mas há casos em que o volume de vendas não é suficiente para gerar o lucro necessário. Isso pode ocorrer pela falta de visão estratégica que engloba as questões de mercado, como fornecedores, concorrentes e consumidores. Desta forma, no mercado competitivo, não basta apenas entender muito bem do produto ou serviço oferecido ao cliente. Por parte do empresário, é preciso visão global que envolve o processo produtivo, sim, mas também é fundamental que esta visão abranja a esfera do marketing, gestão de pessoas e finanças. Cabe considerar que o estudo e a preocupação com as questões financeiras devem estar presentes no dia a dia dos empreendedores para minimizar as graves consequências que um descaso em relação a isso pode acarretar.

De acordo com Ferreira et al. (2012), a falta de planejamento estratégico é um dos principais fatores associados à mortalidade precoce das empresas. Esse planejamento deve ser flexível, para permitir estratégias alternativas de substituição dos planos existentes quando os desdobramentos financeiros divergirem dos padrões esperados. Além do mais, o planejamento financeiro envolve o ajuste adequado dos investimentos a fim de evitar expansão excessiva e uso ineficiente de recursos.

Diante do exposto, o objetivo desta pesquisa é analisar o resultado financeiro das empresas do segmento de alimentação fora do domicílio e divulgar essa análise de forma que possa ser fonte de informação para auxiliar na elaboração de planejamento estratégicofinanceiro das empresas do setor. Em muitos casos, esse planejamento não é realizado, o que contribui para o surgimento de muitos problemas financeiros que podem levar as empresas à falência. Dessa forma, ele constitui fator fundamental para a permanência e êxito dos empreendimentos atuais.

Para alcançar o objetivo geral, foram definidos os seguintes objetivos específicos: elaborar uma demonstração do resultado do exercício (DRE) por empresa pesquisada, assim como uma demonstração com os dados de todas as empresas e outras apresentações por grupos de empresas (lucrativas e deficitárias), para análises mais detalhadas; calcular os principais indicadores financeiros dessas empresas como lucratividade, custo da mercadoria vendida (CMV), salário médio, custo de mão de obra, ocupação do imóvel e tributação; verificar a média de consumo por cliente (tíquete médio); identificar a correlação entre os diversos tipos de custos com os resultados e analisar os principais motivos financeiros causadores de resultados negativos na amostra da pesquisa.

\section{Fundamentação teórica}

Para fundamentar este estudo de acordo com os objetivos propostos, neste tópico, serão tratados assuntos relacionados à DRE e seus componentes, como receitas de venda, CMV, custos com a ocupação do imóvel, mão de obra, salário médio, tributação, tíquete médio, além de tipos de restaurantes e tipos de serviços prestados.

\subsection{Demonstração do Resultado do Exercício (DRE)}

Para as empresas alcançarem seus objetivos é fundamental um adequado planejamento financeiro. A DRE é um dos principais instrumentos nesse processo e é utilizada para demonstrar a dinâmica da empresa, ou seja, como ela está atuando para gerar os resultados planejados.

De acordo com Assaf (2012), a Demonstração do Resultado do Exercício apresenta de forma esquematizada os resultados (lucro ou prejuízo) de uma empresa em um determinado período de tempo. Essa demonstração reflete o efeito das decisões da empresa sobre o desempenho de suas atividades e pode ser utilizada para a análise do custo e benefício dos investimentos.

Segundo Helfert (2000), essas demonstrações do resultado representam o melhor esforço dos administradores de uma empresa para confrontar as receitas com as despesas em um determinado período.

Assim, de forma resumida, os seus principais componentes são: receitas das vendas; CMV; demais despesas com mão de obra, aluguel, tributação, juros pagos e outros gastos operacionais (água, energia, telefone, etc.).

Como ilustração, o Quadro 1 representa um modelo de DRE para o segmento de alimentação fora do domicílio, com CMV de 35\%, despesas administrativas de $55 \%$ (soma dos gastos com mão de obra, ocupação 
Quadro 1. Modelo de DRE para o segmento de alimentação fora do domicílio.

\begin{tabular}{|c|c|c|}
\hline \multicolumn{3}{|c|}{ DEMONSTRAÇÃO DO RESULTADO DO EXERCÍCIO } \\
\hline Especificações & Valores - R\$ & $\%$ \\
\hline RECEITA DE VENDAS & R\$ 100.000,00 & $100,0 \%$ \\
\hline (-) CUSTO DAS MERCADORIAS VENDIDAS (CMV) & $\mathrm{R} \$ \mathbf{3 5 . 0 0 0 , 0 0}$ & $35,0 \%$ \\
\hline (=) LUCRO BRUTO (Margem Bruta) & $\mathrm{R} \$ 65.000,00$ & $65,0 \%$ \\
\hline (-) DESPESAS ADMINISTRATIVAS & $\mathbf{R} \$ 55.000,00$ & $55,0 \%$ \\
\hline Mão de obra & $\mathrm{R} \$ 30.000,00$ & $30,0 \%$ \\
\hline Ocupação & $\mathrm{R} \$ 8.000,00$ & $8,0 \%$ \\
\hline Tributos & $\mathrm{R} \$ 7.500,00$ & $7,5 \%$ \\
\hline OUTRAS DESPESAS (Água, energia, telefone, etc.) & $\mathrm{R} \$ 9.500,00$ & $9,5 \%$ \\
\hline (=) RESULTADO LÍQUIDO (Margem Líquida de Lucro) & $\mathbf{R} \$ 10.000,00$ & $10,0 \%$ \\
\hline
\end{tabular}

Fonte: Adaptado de Martins (2006) e Fonseca (2009). Valores fictícios.

do imóvel, tributos e outras despesas) e lucro líquido de $10 \%$. Todos esses percentuais são calculados em relação à receita de vendas.

Esses valores são fictícios, mas os percentuais foram baseados em Fonseca (2009), conforme Quadro 2. Para a determinação do preço de venda praticado pelos restaurantes, o autor mostra um modelo de composição dos gastos pelo Método Indexador Texas Restaurant Association (TRA). Nesse modelo, observa-se CMV de $35 \%$, gastos operacionais de $25 \%$ e folha de pagamento de $30 \%$. Neste caso, a empresa teria um lucro de $10 \%$ de seu faturamento.

Dessa forma, foram consideradas como gastos operacionais as despesas administrativas, com exceção dos gastos com a mão de obra. Assim, esses gastos operacionais de $25 \%$ são os gastos com aluguel (7\%), tributos (8\%) e demais despesas (10\%), como água, energia, telefone, manutenção, segurança, etc.

\subsection{Receita de vendas}

A receita de vendas é o valor nominal referente às vendas de bens ou à prestação de serviços em um determinado período. Segundo Assaf (2012), elas devem ser registradas no momento da venda, independentemente de seu vencimento. Todos os esforços e custos incorrem no momento da venda ou da prestação de serviço, por isso não tem sentido considerá-los apenas no recebimento, caso as vendas sejam realizadas a prazo.

O preço de venda é um dos determinantes do volume das receitas. No mercado competitivo atual, os custos são fundamentais para o estabelecimento dos preços de venda, por isso há uma constante preocupação por parte dos empreendedores em reduzi-los cada vez mais. Porém, de acordo com Martins (2006), devido à alta concorrência, as empresas já não podem mais definir os seus preços de venda com base apenas nos custos, mas devem considerar os preços praticados no mercado. Em outras palavras, elas devem estar atentas ao consumidor, qual a disposição que ele
Quadro 2. Modelo financeiro de custos para restaurantes (método TRA).

\begin{tabular}{|l|c|}
\hline \multicolumn{1}{|c|}{ GASTOS } & $\begin{array}{c}\text { PERCENTUAL DA } \\
\text { RECEITA }(\boldsymbol{\%})\end{array}$ \\
\hline Lucro & 10 \\
\hline Folha de pagamento & 30 \\
\hline Gastos operacionais & 25 \\
& $\begin{array}{c}\text { (Aluguel, 7; Tributos, 8; } \\
\text { Outras despesas, 10) }\end{array}$ \\
\hline TOTAL & 65 \\
\hline Receita & 100 \\
\hline Total de gastos & 65 \\
\hline CMV & 35 \\
\hline
\end{tabular}

Fonte: Adaptado de Fonseca (2009).

tem em pagar pelos produtos adquiridos ou serviços recebidos. Se as empresas não conhecerem a intenção do cliente, poderão estabelecer preços que, por ora, podem estar além do que os clientes podem pagar, reduzindo suas vendas, ou ainda podem definir preços aquém da disposição do cliente, o que pode aumentar muito suas vendas, mas minimizar seus resultados.

Dependendo do tipo de restaurante, ou tipo de serviço prestado, esses preços podem ser maiores ou menores. Para uma alimentação rápida, um almoço de trabalhadores que optam por cardápio mais simples, por exemplo, é importante que o preço seja baixo. De acordo com Blanck et al. (2007), numa pesquisa feita com o público trabalhador americano, o preço é considerado o terceiro fator mais importante para a escolha do local do almoço nos dias de trabalho $(20,8 \%)$. O primeiro é a conveniência $(34,3 \%)$, seguida pelo sabor $(27,8)$. A saúde ficou apenas em quarto lugar, com $17,1 \%$.

Assim, o negócio só será bem sucedido se forem satisfeitas as necessidades e expectativas dos clientes que se tornam cada vez mais exigentes frente às variedades de opções de produtos e serviços que o mercado oferece. Com o avanço tecnológico, os 
produtos e serviços tornam-se muito parecidos e com qualidade muito elevada. $\mathrm{O}$ mercado não cede lugar a empreendimentos sem qualidade. Assim, o diferencial, em muitos casos, será a forma de atendimento dispensada ao cliente que comprará de quem the oferecer maior rapidez, segurança, comodidade, cordialidade, preço adequado, marca associada à divulgação do produto na mídia, enfim, um atendimento completo e diferenciado de acordo com as características de cada consumidor. Dessa forma, as receitas com as vendas serão suficientes para superar todos os custos e despesas, gerando resultado positivo.

\subsection{Custo das Mercadorias Vendidas (CMV)}

O CMV representa os custos incorridos no momento da venda ou na prestação de serviços, especialmente o custo da matéria-prima. O seu cálculo em determinado período, de acordo com Martins (2006), pode ser feito da seguinte maneira conforme a Expressão 1:

$$
\mathrm{CMV}=\mathrm{EI}+\mathrm{C}-\mathrm{EF}
$$

EI é o valor do estoque no início do período; $\mathrm{C}$ é o valor das compras realizadas no período; e EF é o valor do estoque final.

$\mathrm{O}$ valor do estoque deve ser sempre baseado no custo de aquisição. Quando há estoques de mesmo produto com diferentes custos de aquisição podem ser usados alguns critérios de avaliação dos estoques. O critério PEPS (Primeiro a Entrar, Primeiro a Sair) é utilizado quando a empresa considera os custos mais antigos na composição do CMV do período. $\mathrm{O}$ UEPS (Último a Entrar, Primeiro a Sair) é utilizado quando a empresa considera os custos mais recentes. Martins (2006) também mostra o PMP (Preço Médio Ponderado). Nesse caso, considera-se a média dos custos, tendo como pesos para os cálculos as quantidades adquiridas com seus respectivos custos.

\subsection{Custo de mão de obra}

Segundo Araujo (2006), as pessoas da organização que formam o corpo funcional contribuem para a instalação de um clima organizacional favorável que conduz a resultados nos negócios ou a outras atividades de interesse da organização. Esse é o chamado capital humano que serve de combustível para movimentar a máquina e fazer com que ala chegue ao seu destino. Para Chiavenato (2005), esse capital humano também pode ser chamado de talento humano, nas organizações que dão maior valor para as pessoas, pois o termo capital pode passar a impressão de que a empresa trata as pessoas como objeto ou matéria.
Porém, esse valor das pessoas é de difícil mensuração, embora, em uma empresa, quase tudo possa ser mensurável. Na medida do possível, todas as atividades que envolvem os negócios devem mesmo ser valoradas para que haja um controle dos resultados financeiros e econômicos da organização. Contudo, nem todos os fatores podem ser quantificados ou medidos em termos de valor monetário. Um desses fatores que dificilmente pode ser transformado em medida monetária são as pessoas, que contribuem com os processos produtivos e são fundamentais para gerar valor às empresas. Ou seja, raramente se consegue chegar ao valor aproximado que é adicionado às empresas pelo trabalho das pessoas, pelo talento humano. O que significa que é muito difícil estabelecer o valor econômico agregado pelas pessoas à empresa da qual elas fazem parte.

Em outra perspectiva, que não é a do valor do trabalho das pessoas, mas sim a dos custos que essas pessoas representam para as empresas, os cálculos são mais simples, pois podem ser adequadamente mensuráveis por meio dos cálculos trabalhistas que estudaremos a seguir. Chamaremos esta perspectiva de Custo de Mão de Obra. Dessa forma, é muito importante que as empresas façam os cálculos corretamente em relação a esses custos, incluindo todos os encargos e acréscimos legais, para que não haja custos esquecidos, ou desconsiderados ao longo dos processos. Se os custos não forem bem calculados, o resultado positivo esperado pode não ser alcançado, ou por ter sido precariamente planejado, ou por haver erros de cálculos em relação aos custos, o que pode inviabilizar negócios ou contribuir para as dificuldades financeiras que, em muitos casos, levam as empresas ao fracasso. Nesse sentido, a falta de competência na gestão é apontada como um dos fatores associados à mortalidade precoce das empresas de acordo com pesquisa realizada por Ferreira et al. (2012).

Assim, segundo Braga (2008), quando a empresa não goza de algum benefício fiscal, os encargos sobre a folha de pagamento são os seguintes conforme Quadro 3.

Quadro 3. Encargos sociais no Brasil.

\begin{tabular}{|l|c|}
\hline \multicolumn{1}{|c|}{ Encargos } & Valor do encargo \\
\hline $13^{\circ}$ salário & $8,33 \%$ \\
\hline Férias & $8,33 \%$ \\
\hline $13^{\circ}$ férias & $2,7 \%$ \\
\hline INSS & $27,00 \%$ \\
\hline FGTS & $8,00 \%$ \\
\hline INSS sobre férias e $13^{\circ}$ & $5,25 \%$ \\
\hline FGTS sobre férias e $13^{\circ}$ & $1,56 \%$ \\
\hline Total & $61,25 \%$ \\
\hline
\end{tabular}

Fonte: Braga (2008). 
Todavia, no caso de empresas tributadas pelo Sistema Integrado de Pagamento de Impostos e Contribuições das Microempresas e Empresas de Pequeno Porte (SIMPLES), o imposto do Instituto Nacional de Seguridade Social (INSS) já está contemplado como encargo da empresa pela Contribuição Patronal Previdenciária (CPP). Dessa forma, o total dos encargos sociais é de $29 \%$ sobre a folha de pagamento dessas empresas. Além disso, em determinados casos, as empresas ainda arcam com despesas como transporte e alimentação.

A qualificação é outro aspecto importante que deve ser considerado no custo da mão de obra. A falta de mão de obra qualificada também é um fator apontado pela pesquisa realizada por Ferreira et al. (2012) como causa da mortalidade precoce das empresas. Essa qualificação demanda custos por parte das empresas, que podem ser investimento em capacitação, treinamento e formação para o desenvolvimento das competências das pessoas envolvidas com a organização. Com pessoal qualificado, uma organização pode enfrentar a competitividade do mercado. Esta competitividade pode ser entendida como a competição implacável do mercado somada a essa competência, que é fundamental para que as pessoas possam atuar contribuindo com a qualidade dos produtos e serviços oferecidos nesse mercado, gerando resultado positivo.

Em relação à gestão de pessoas, Knight (2005) enfatiza que as principais ferramentas para administrar de forma eficaz os custos de mão de obra são: a escala de trabalho, os guias de equipe e a participação dos colaboradores no planejamento das atividades. A escala de trabalho é uma forma de utilização do número correto de trabalhadores. Ela pode ser menos flexível quando a quantidade de clientes for previsível e deve ser preparada para cada categoria de funcionários. Os guias de equipes têm a finalidade de apresentar em linhas gerais as necessidades dos funcionários e devem ser preparados pelo gerente do estabelecimento, com base nos horários de funcionamento e no tipo de serviço prestado pelo estabelecimento. Sobre a participação dos colaboradores no planejamento, cabe destacar que é uma prática presente na administração moderna e democrática, que sabe aproveitar as competências de todos os que participam do processo produtivo. A análise e o aproveitamento das ideias e sugestões de quem vivencia o dia a dia da empresa possibilita a resolução mais rápida de problemas e a inovação dos processos, contribuindo com a redução dos custos e com a ampliação dos resultados.

\subsection{Custo da ocupação}

Para Knight (2005), os gastos com a ocupação de um espaço para o desempenho das atividades comerciais são considerados custos fixos, mas, quando comparados com o volume de vendas, eles variam entre $2 \%$ e $10 \%$ desse volume, podendo chegar a percentuais maiores. No Brasil, eles variam de acordo com a localização e zoneamento do imóvel, ou por outros fatores. Em alguns casos, como em estabelecimentos de shoppings, os contratos de aluguel podem ser firmados com valores flutuantes de acordo com as variações do faturamento.

Em relação aos estabelecimentos de alimentação fora do domicílio, para Zanella (2007), devem ser considerados alguns aspectos ao alugar um espaço para a instalação de um restaurante, como posição ou localização, adequação ao nível e porte do restaurante, infraestrutura, índices de poluição, exigência de equipamentos especiais, facilidade de acesso, mão de obra disponível, entre outros. Sobre o contrato de aluguel, esse autor afirma que algumas questões devem ser observadas, principalmente quanto ao prazo e possibilidade de renovação. São recomendados contratos com mais de cinco anos de duração que podem ser renovados judicialmente.

\subsection{Tipos de restaurantes e de serviços}

Há duas classificações diferentes a serem consideradas nesse segmento de alimentação fora do lar. Uma é em relação ao tipo de restaurante, e outra quanto ao tipo de serviço prestado.

\subsubsection{Tipos de restaurantes}

Quanto ao tipo utilizado nessa pesquisa, os restaurantes podem ser classificados como lanchonete ou sanduicheria, cafeteria ou confeitaria, restaurante de opções variadas e restaurante de especialidade (comida oriental, italiana, árabe, francesa, mexicana, churrascaria, internacional, entre outros).

Outra forma de classificação quanto ao tipo é a utilizada por Braga (2008), Quadro 4, indicando que o tipo econômico tem maior CMV e, consequentemente,

Quadro 4. Parâmetros de classificação dos restaurantes no Brasil.

\begin{tabular}{|l|c|c|c|}
\hline \multicolumn{1}{|c|}{ Tipo } & CMV & Rotatividade & Tíquete médio(R\$) \\
\hline Econômico & $35 \%$ & 3 a 5 & Até 15,00 \\
\hline Familiar & $33 \%$ & 2 a 4 & 15,00 a 35,00 \\
\hline Moderado & $30 \%$ & 1,5 a 2,5 & 35,00 a 70,00 \\
\hline Luxo & $25 \%$ & Até 1,5 & Acima de 70,00 \\
\hline
\end{tabular}

Fonte: Braga (2008). 
menor lucro. Nesse tipo, o tíquete médio é menor, e a rotatividade (número de vezes que um mesmo assento é utilizado durante o período de uma refeição) é maior. Com a maior rotatividade, é possível otimizar o uso do espaço e reduzir o valor do aluguel, para compensar o elevado CMV e o baixo valor do tíquete médio. O inverso acontece gradativamente quando o restaurante é do tipo familiar, moderado e luxo.

\subsubsection{Tipo de serviço prestado}

Em relação ao tipo de serviço, os dois mais utilizados são à la carte e self-service. Segundo Zanella (2007), à la carte é a técnica de serviço em que é apresentada ao cliente a carta de menu ou cardápio, no qual estão discriminados os pratos com seus respectivos preços. Self-service é um sistema de serviço rápido, sem a necessidade da participação do garçom, tanto os alimentos quanto os pratos, talheres e utensílios ficam à disposição do cliente para que ele se sirva. Nesse caso, o sistema pode ser a peso (por quilo) e na modalidade de preço fixo. De acordo com Santos et al. (2011), o restaurante por peso é uma modalidade de serviço muito utilizada na realidade brasileira e representa uma alternativa saudável de alimentação fora de casa.

\subsubsection{Tíquete médio}

O tíquete médio é o valor consumido por pessoa em uma refeição. Pesquisas para a identificação de seu valor em determinado local ou região são de fundamental importância para a definição do valor do auxílio-alimentação das empresas que concedem esse benefício ao trabalhador.

\subsection{Tributação}

A carga de tributos também é um fator associado à mortalidade precoce das empresas de acordo com Ferreira et al. (2012). Ela pode representar uma ameaça para a maioria das empresas que ainda não se adaptaram ao mercado competitivo. Conforme Rebello (2013), no Brasil, ela já alcançava, em 2009, cerca de $35,8 \%$ do Produto Interno Bruto (PIB), o que fazia o país ter uma das maiores cargas tributárias mundiais, abaixo apenas de poucos países desenvolvidos como França (46\%), Itália (42\%) e Alemanha (40\%).
Essa situação continuou muito parecida nos anos seguintes, pois, de acordo com os dados divulgados pela Receita Federal (Brasil, 2013), a carga tributária no Brasil, somando as três esferas de governo (municipal, estadual e federal), em 2011, atingiu $35,31 \%$ (PIB). Calcula-se esse percentual, comparando a arrecadação tributária ( $\mathrm{R} \$ 1,463$ trilhão) com o total das riquezas produzidas no país durante o ano de 2011 (R \$ 4,143 trilhões).

Em relação às empresas da pesquisa, a maioria é micro e pequena empresa, e esse tipo de empresa tem regime de tributação especial conforme classificação abordada a seguir.

\subsubsection{Classificação quanto ao porte das empresas}

As empresas beneficiadas pelo SIMPLES, regido pela Lei Complementar no 123 de 14/12/2006, são as micro e pequenas empresas. As microempresas são as que faturam até $\mathrm{R} \$ 360.000,00$ por ano, e as pequenas empresas são as que faturam desse valor até $\mathrm{R} \$ 3.600 .000,00$. As alíquotas do SIMPLES para as empresas de alimentação fora do lar, que são caracterizadas como indústrias, vão desde 4,5\% sobre o faturamento de até $\mathrm{R} \$ 180.000,00$ por ano, podendo chegar a $12,11 \%$ para as que faturam entre $\mathrm{R} \$ 3.420 .000,01$ e $\mathrm{R} \$ 3.600 .000,00$. Esse regime de tributação engloba os impostos IRPJ (Imposto de Renda Pessoa Jurídica), CSLL (Contribuição Social sobre o Lucro Líquido), Cofins (Contribuição para Fins Sociais), PIS/Pasep (Programa de Integração Social/Programa de Formação do Patrimônio do Servidor Público), CPP (Contribuição Patronal Previdenciária), ICMS (Imposto sobre Circulação de Mercadorias e Serviços) e IPI (Imposto sobre Produtos Industrializados).

Outra classificação é elaborada pelo SEBRAE (2011), de acordo com o número de funcionários, conforme Quadro 5.

\section{Procedimentos metodológicos}

O foco desta pesquisa é a análise dos resultados financeiros das empresas filiadas à Associação Brasileira de Bares e Restaurantes (ABRASEL), situadas na cidade de Florianópolis. A pesquisa foi realizada entre os meses de janeiro e maio de 2013

Quadro 5. Classificação das empresas pelo critério de pessoas empregadas.

\begin{tabular}{|l|l|l|}
\hline \multicolumn{1}{|c|}{ Porte } & \multicolumn{1}{c|}{ Indústria } & \multicolumn{1}{c|}{ Comércio e Serviços } \\
\hline Microempresas & Até 19 empregados & Até 9 empregados \\
\hline Pequenas & De 20 a 99 empregados & De 10 a 49 empregados \\
\hline Médias & De 100 e 499 empregados & De 50 a 99 empregados \\
\hline Grandes & Mais de 500 funcionários & De 100 empregados ou mais \\
\hline
\end{tabular}

Fonte: SEBRAE (2011). 
por meio da aplicação de um questionário enviado aos endereços eletrônicos dos estabelecimentos com a utilização do software chamado LimeSurvey, que utiliza uma metodologia com respostas anônimas enviadas via internet. Assim, o respondente tem a segurança de que não será identificado e seus dados financeiros particulares não serão divulgados. Também foram feitas ligações telefônicas para confirmar a chegada do questionário aos destinatários, bem como sua procedência.

De acordo com informações pesquisadas no sítio eletrônico da ABRASEL (2013), os associados, que constituíram a população da pesquisa, são 98 restaurantes, 19 bares e 9 lanchonetes/sanduicherias. Desse total de 126 empresas, apenas 28 responderam, o que corresponde a $22 \%$ da população. Dessa forma, não foi possível inferir os resultados para a população. Assim, a análise reflete apenas a situação das empresas respondentes.

\subsection{Variáveis da pesquisa}

Como o foco do estudo é a questão financeira, foi necessário pesquisar informações para a elaboração das DREs. Assim, para fazer o instrumento de pesquisa, consideraram-se os principais elementos que compõem uma DRE, de modo que, com as respostas, fosse possível montar uma demonstração para cada empresa, assim como uma apresentação para todas elas juntas e ainda por tipo de estabelecimentos (à la carte, serf-service, etc.). Optou-se por essa metodologia, de construir a DRE, pela dificuldade de captar essas demonstrações prontas, elaboradas pelas empresas e que representem a realidade, pois grande parte das empresas apresenta demonstrações para o fisco que não são adequadas para a análise financeira. Uma das dificuldades, por exemplo, é conseguir informações que revelem o faturamento real das empresas ou o seu lucro. Para sanar essa dificuldade, foram feitas perguntas como: Qual o valor do tíquete médio e a quantidade de clientes atendidos por mês? Com essas informações, calcula-se o faturamento mensal. As outras questões de ordem financeira necessárias para completar a DRE foram: Qual o valor médio gasto com matéria-prima?; Qual o custo mensal da folha de pagamento, fora os encargos?; Qual o custo mensal com a ocupação do imóvel, incluindo taxas de condomínio e impostos, como o Imposto Predial e Territorial Urbano? Além dessas, o questionário continha perguntas sobre a caracterização da empresa relacionadas à quantidade de funcionários; ao tipo de serviço oferecido e ao tipo de restaurante; à modalidade de recebimento das vendas ou forma de pagamento pelo cliente e ao percentual de rotatividade dos funcionários. Esse questionário está descrito no Apêndice 1.

\subsection{Coleta e tratamento dos dados}

O questionário foi respondido por 28 estabelecimentos, dos quais cinco foram desconsiderados. Desses cinco, três não responderam todas as questões, e dois apresentaram respostas incoerentes. Assim, foram considerados 23 respondentes relacionados no Apêndice 2. Para facilitar o tratamento dos dados e a construção das tabelas, foram utilizadas as seguintes siglas:

- (ER) Empresa respondente. Como são 23, haverá de ER1 até ER23.

- Quanto ao tipo de serviço oferecido: (SP) self-service por peso; $(A L)$ à la carte; (DV) diversos tipos, incluindo os dois anteriores e também livre por pessoa.

- Para os tipos de restaurantes: (ROV) restaurante de opções variadas; (RES) restaurante de especialidade; (LCH) lanchonete; (SAN) sanduicheria; $(\mathrm{BCH})$ bar e choperia; $(F A F)$ fast food.

- No Apêndice 3: (CMV) Custo da Mercadoria Vendida; (LB) Lucro Bruto; (MO) Mão de Obra; (ES) Encargos Sociais; (COI) Custo de Ocupação do Imóvel; (IMP) Impostos; (ODP) Outras Despesas; (LL) Lucro Líquido.

\section{Análise dos resultados}

Os dados da pesquisa foram compilados e estão no Apêndice 2, que mostra as informações fornecidas pelas 23 empresas que responderam à pesquisa e estão numeradas de 1 a 23. Esse apêndice também mostra a somatória e a média dos valores das 22 primeiras, que são micro e pequenas empresas, de acordo com a classificação do SEBRAE (2011) (Quadro 5).

Entre as 23 empresas respondentes, há 19 restaurantes, 3 lanchonetes/sanduicherias e 1 bar. Dos restaurantes, 12 oferecem serviços à la carte, 3 são self-service (por peso), e 4 apresentam ao mesmo tempo esses dois tipos de serviço. Em relação ao tipo de alimentação servida, 10 são restaurantes de especialidades do tipo comida oriental, italiana, árabe, francesa, mexicana, churrascaria, comida internacional e outros; 8 são restaurantes de opções variadas; e 1 é fast food.

De acordo com as respostas da Questão 1, entre essas 22 empresas, 13 são microempresas (possuem até 19 funcionários), e 9 são pequenas (possuem de 20 a 100 funcionários). Entre as 23 que responderam à pesquisa, apenas 1 é média empresa, pois possui 200 funcionários (ER 23). Enquanto somente esta empresa emprega 200 pessoas, as demais 22 micro e pequenas empresas empregam juntas 466 pessoas, sendo que a menor possui 3 empregados, e a maior, 70 . 
Essa média empresa é um restaurante do tipo fast food e deve ser analisada isoladamente por ter características específicas devido ao seu porte e tipo.

\section{1 Única média empresa respondente (ER 23)}

O CMV da ER 23, única média empresa que respondeu à pesquisa, representa $15,4 \%$ das vendas. Os outros principais custos dessa empresa estão divididos da seguinte forma: $7,7 \%$ com ocupação e $11,2 \%$ com a mão de obra. Principalmente este último custo fica muito abaixo da média das demais pesquisadas, que é de 26,56\%, conforme Quadro 6. A ER 23 possui elevadíssimo índice de rotatividade de seus funcionários $(80 \%)$, enquanto a média das demais é de 29,70\%, conforme Apêndice 2. Quanto ao seu CMV (15,4\%), este fica abaixo da metade da média das demais, que é de $36,34 \%$. De forma geral, os custos dessa empresa ficam bem abaixo dos custos das demais pesquisadas e, consequentemente, sua margem de lucro bruto, bem acima da média do segmento. Isso pode estar relacionado ao porte da empresa, é uma média empresa e tem volumes de vendas bem acima das demais. Em relação ao número de clientes, ela atende 130.000 por mês, enquanto a soma dos clientes de todas as outras chega a 125.544 , conforme Apêndice 2.

\subsection{Análise das 22 micro e pequenas empresas}

O Quadro 6 mostra uma DRE feita com a somatória dos valores das 22 empresas que responderam ao questionário e são micro e pequenas empresas.

Dependendo do tipo de análise, pode ser mais indicada a utilização da média ponderada, ou é mais lógica a utilização da média simples. Por isso, a DRE mostra os percentuais de análise vertical com os dois tipos de média. A ponderada é o cálculo do percentual de cada valor do DRE, Quadro 6, em relação à receita de vendas. A média simples é a somatória dos valores de cada empresa, dividida por 22, de acordo com o Apêndice 2.

Dessa forma, considerando os dados do Quadro 6, percebe-se que as 22 empresas juntas tiveram um faturamento de $\mathrm{R} \$ 3.120 .312,00$ e um lucro líquido de $\mathrm{R} \$ 432.679,18$ que representa $13,87 \%$ do faturamento pelo cálculo da média ponderada e $6,39 \%$ pela média simples. Esse resultado é auferido admitindo-se que a conta "Outras despesas" seja de $10 \%$ do faturamento, que é uma estimativa de acordo com a teoria estudada (Quadro 2), já que esse dado não foi objeto da pesquisa. Assim, esses valores foram projetados para que fosse apurado o lucro líquido das empresas. Cada um dos componentes da DRE será analisado detalhadamente a seguir.

\subsubsection{Receita de vendas}

Para se evitar uma possível resistência por parte das empresas pesquisadas em informar o valor de suas receitas de vendas, não houve uma questão específica para verificar esse valor. Para sanar essa dificuldade, foram formuladas questões relacionadas ao valor do tíquete médio e à quantidade de clientes atendidos por mês. O produto entre essas duas informações resulta no valor do faturamento mensal ou receitas de vendas. $\mathrm{O}$ valor das receitas das 22 empresas pesquisadas está relacionado no Apêndice 3 e é a primeira informação da DRE (Quadro 6), cujo valor total chegou a $\mathrm{R} \$ 3.120 .312,00$.

\subsubsection{Tíquete médio e quantidade de clientes}

$\mathrm{O}$ valor do tíquete médio variou entre $\mathrm{R} \$ 12,00$ e R $\$ 75,00$. A média simples (somatória do valor do tíquete médio de cada uma das 22 empresas, dividida por 22) é de $\mathrm{R} \$ 34,18$. Contudo, a média

Quadro 6. DRE - Somatória dos valores das 22 micro e pequenas empresas respondentes.

\begin{tabular}{|c|c|c|c|}
\hline \multicolumn{4}{|c|}{ DEMONSTRAÇÃO DO RESULTADO DO EXERCÍCIO } \\
\hline Especificações & $\mathbf{R} \$$ & $\begin{array}{c}\text { Média } \\
\text { Ponderada }\end{array}$ & $\begin{array}{c}\text { Média } \\
\text { Simples }\end{array}$ \\
\hline RECEITA DE VENDAS & $\mathbf{R} \$ 3.120 .312,00$ & $100,00 \%$ & $100,00 \%$ \\
\hline (-) CUSTO DA MERCADORIA VENDIDA (CMV) & $\mathrm{R} \$ \mathbf{1 . 0 6 4 . 9 2 0 , 0 0}$ & $34,13 \%$ & $36,34 \%$ \\
\hline (=) LUCRO BRUTO (Margem Bruta de Lucro) * & $\mathrm{R} \$ 2.055 .392,00$ & $65,87 \%$ & $63,66 \%$ \\
\hline (-) DESPESAS ADMINISTRATIVAS & $\mathbf{R} \$ 1.622 .712,82$ & $52,00 \%$ & $57,27 \%$ \\
\hline • Mão de obra & $\mathrm{R} \$ 756.761,73$ & $24,25 \%$ & $26,56 \%$ \\
\hline • Ocupação & $\mathrm{R} \$ 248.856,00$ & $7,98 \%$ & $12,41 \%$ \\
\hline - Tributos & $\mathrm{R} \$ 305.063,89$ & $9,78 \%$ & $8,30 \%$ \\
\hline - OUTRAS DESPESAS (Água, energia, telefone, etc.) ${ }^{* *}$ & $\mathrm{R} \$ 312.031,20$ & $10,00 \%$ & $10,00 \%$ \\
\hline (=) RESULTADO LÍQUIDO (Margem Líquida de Lucro)* & $R \$ 432.679,18$ & $13,87 \%$ & $6,39 \%$ \\
\hline
\end{tabular}

Fonte: Elaborado pelo autor. *O lucro bruto e o lucro líquido não são informações da pesquisa, foram calculados. **Outras despesas: esse valor corresponde a $10 \%$ das vendas com fundamentado no Quadro 2. 
ponderada (somatória das receitas de vendas mensais das 22 empresas, dividida pelo total de clientes atendidos no mês por todas elas) é de $\mathrm{R} \$ 24,85$. Considerando a classificação de Braga (2008) em relação ao tíquete médio (Quadro 4), três empresas são do tipo econômico (tíquete médio até $\mathrm{R} \$ 15,00$ ), uma é de luxo (tíquete médio acima de $\mathrm{R} \$ 70,00$ ); e as demais são do tipo familiar ou moderado, com esse valor entre $\mathrm{R} \$ 15,00$ e $\mathrm{R} \$ 70,00$.

$\mathrm{O}$ valor do tíquete médio nos restaurantes que oferecem serviço à la carte é de $\mathrm{R} \$ 41,18$ pela média simples e $\mathrm{R} \$ 37,15$ pela média ponderada, enquanto o dos restaurantes self-service por peso é de $\mathrm{R} \$ 19,00$ pela média simples e $\mathrm{R} \$ 18,90$ de acordo com a média ponderada.

Em relação à quantidade de clientes, as 22 empresas atendem, em média, 125 mil por mês. A menor atende 400 clientes, e a maior, cerca de 34 mil.

\subsubsection{Modalidade de recebimento das vendas}

Quanto ao recebimento das vendas, o cartão de crédito é a modalidade mais utilizada com $35 \%$ do total, seguido pelo cartão de débito $(25 \%)$ e dinheiro (25\%). O tíquete refeição corresponde a $10 \%$, e o cheque a $5 \%$. Esses valores são aproximados.

\subsubsection{Custo da Mercadoria Vendida - CMV}

O CMV médio percentual ficou em 36,2\% (média simples), sendo que o menor índice foi $19 \%$ e o maior $60 \%$, conforme Apêndice 3. Geralmente, o CMV é o maior custo para as empresas de alimentação fora do lar, porém 4 empresas apresentaram custo de mão de obra maior do que o CMV. Para os restaurantes self-service por peso, o CMV alcançou $49,6 \%$, bem acima do CMV dos restaurantes à la carte $(35,24 \%)$. Os restaurantes de serviços diversos (self-service por peso ou com preço fixo por pessoa e também à la carte) tiveram a média de $37,05 \%$, enquanto os outros (lanchonete, sanduicheria e bar) apresentaram CMV de $28,50 \%$.

\subsubsection{Custo da mão de obra}

O custo da mão de obra é um dos mais altos custos para as empresas do ramo, ficando abaixo apenas do CMV. A média do custo de mão de obra para as 22 empresas pesquisadas é de 26,50\% (média simples). A média salarial, sem os encargos sociais, ficou em $R \$ 1.363,38$, variando entre $\mathrm{R} \$ 606,06 \mathrm{e}$ $\mathrm{R} \$ 2.500,00$. Para os restaurantes self-service e de serviços diversos, os gastos com mão de obra mais encargos representam $26,38 \%$ das vendas, enquanto para os à la carte representam $28,8 \%$.

\subsubsection{Rotatividade da mão de obra}

A rotatividade média anual da mão de obra alcançou o índice de $34,11 \%$. Assim, pode-se considerar que dos 466 funcionários das 22 empresas, em média, 159 são substituídos por ano. Esse índice é maior no grupo lanchonete, sanduicheria e bar que alcançou $42,0 \%$, enquanto nos restaurantes ficou em $26,7 \%$.

De acordo com os dados das empresas pesquisadas, pode-se afirmar, com nível de significância de $95 \%$, que a rotatividade dos funcionários não tem correlação com o valor dos salários, pois o valor do coeficiente de correlação linear entre essas duas variáveis (percentual de rotatividade e salário médio) é de 0,09 negativo. Como explica Lapponi (2000), o coeficiente de correlação linear expressa a correlação que existe entre os pares das variáveis analisadas. Quando o seu valor é próximo de +1 , expressa forte correlação positiva; quando estiver próximo de zero, existe uma fraca correlação; quando for igual a zero, não existe nenhuma relação; quando próximo de -1 , há uma forte correlação negativa.

Outro aspecto a ser considerado sobre essa rotatividade é a questão da motivação para o trabalho. A baixa correlação entre rotatividade dos funcionários e níveis salariais também pode ser explicada com base na teoria da motivação para o trabalho proposta por Herzberg. Esse estudo chamado de Teoria dos Dois Fatores, como explica Maximiano (2008), aponta o salário como um fator motivacional extrínseco ou higiênico. Esse tipo de fator apenas reduz a insatisfação para o trabalho, não causa uma motivação duradoura, ao contrário dos fatores intrínsecos ou motivacionais como o próprio trabalho e a realização pessoal, que produzem a duradoura satisfação dos trabalhadores. Dessa forma, pode-se depreender que os salários mais altos apenas reduzem a insatisfação e, como acontece nas empresas que responderam à pesquisa, não são suficientes para motivar de forma a reter os funcionários no emprego.

\subsubsection{Custo da ocupação do imóvel}

O custo da ocupação do imóvel (aluguel, condomínio, imposto predial, etc.) na média simples das 22 empresas representa $12,41 \%$ das vendas, variando de $3,3 \%$ a $28,6 \%$. Grande parte dos custos fixos se concentra entre o custo de ocupação e o custo da mão de obra. Esses dois custos juntos representam em torno de $68 \%$ dos custos fixos das empresas pesquisadas e $39 \%$ de suas receitas. O coeficiente de correlação entre o percentual que esses dois custos representam das vendas e o lucro líquido das empresas pesquisadas é 0,86 negativo, o que mostra que há correlação negativa entre eles, com nível de significância de 95\%. Ou seja, quanto maior o percentual desses dois custos em relação às vendas, menor é o lucro da empresa, e vice-versa. Isso já não ocorre de forma tão incisiva com o CMV, 
pois o coeficiente de correlação entre o percentual de CMV e o lucro líquido é de 0,48 negativo. Essa análise indica que a atenção dos administradores em relação à adequação dos níveis de venda com esses dois custos fixos (mão de obra e ocupação do imóvel) deve ser uma preocupação mais intensa do que a busca pelo aumento da margem bruta de lucro (CMV mais baixo).

\subsubsection{Tributação}

A média das despesas com tributação para as 22 empresas pesquisadas é de $8,4 \%$ (média simples). Duas empresas são tributadas com a alíquota mínima de $4,5 \%$, e três com a máxima de $12,11 \%$, de acordo com a tabela de tributação do SIMPLES. As demais empresas têm alíquotas entre essas duas. $\mathrm{O}$ total de impostos pagos apenas nessa modalidade de tributação pelas 22 empresas é de, aproximadamente, $\mathrm{R} \$ 305.000,00$ por mês.

\subsubsection{Lucratividade}

A lucratividade média dessas empresas em relação ao seu faturamento é de 13,9\% pela média ponderada e 6,7\% pela média simples, totalizando $\mathrm{R} \$ 432.679,00$ de lucro líquido por mês. Porém, a média aritmética é um parâmetro que deve ser considerado com certa restrição em análises desse tipo, pois pode haver muitos desvios em relação a essa média. Os resultados financeiros (lucro ou prejuízo) dessas empresas pesquisadas espelham essa situação. Por um lado, algumas empresas tiveram margem de lucro que superaram $30 \%$, por outro lado várias tiveram prejuízos acima dos $30 \%$. Por esse motivo, a análise da lucratividade merece destaque.

Entre essas 22 micro e pequenas empresas, conforme as DREs (Apêndice 3), seis (27\%) tiveram prejuízos, duas $(9 \%)$ apresentaram margem de lucro líquido abaixo de $1 \%$ das vendas, e catorze (64\%) tiveram lucros expressivos.
Diante desses números, podemos concluir que eles confirmam a situação difícil de muitas micro e pequenas empresas, conforme as pesquisas do SEBRAE (2011) que apontam o grande número de empresas que fecham suas portas por problemas financeiros.

Seguem as análises específicas para os dois grupos de empresas: as lucrativas e as que apresentaram prejuízo.

\subsubsection{Empresas lucrativas}

Para análise das empresas lucrativas, elaborou-se uma DRE com a somatória dos valores das 16 empresas que tiveram resultado positivo conforme Quadro 7.

Não há destaque em alguns pontos específicos nessa DRE. O que se percebe é que as margens de lucro são maiores devido aos menores índices percentuais de todos os custos, exceto dos tributos, que são evidentemente maiores porque essas empresas têm faturamento maior do que as deficitárias. Nesse sentido, vale destacar que essas 16 empresas lucrativas representam $73 \%$ das 22 empresas em análise, mas o faturamento delas representa $92,4 \%$ do total. Dessa forma, pode-se argumentar novamente que é o volume de vendas adequado aos custos da empresa que a faz ter resultado financeiro positivo.

\subsubsection{Empresas com prejuízo}

Todas as 6 empresas que apresentaram prejuízo são microempresas, de acordo com a classificação do SEBRAE (2011), pois possuem menos de 19 funcionários. Essa pesquisa mostra que quanto menor a empresa, maiores são as possibilidades de prejuízo; e, por outro lado, quanto maior a empresa, maiores as possibilidades de lucro. Isso é revelado, considerando o nível de significância de $95 \%$, com o coeficiente de correlação de 0,79 entre as variáveis lucro líquido e faturamento.

O Quadro 8 mostra as médias dos valores apresentados pelas 6 empresas que apresentaram prejuízo.

Quadro 7. DRE - Somatória dos valores das 16 micro e pequenas empresas lucrativas.

\begin{tabular}{|l|c|c|}
\hline \multicolumn{3}{|c|}{ DEMONSTRAÇÃo DO RESULTADO DO EXERCíCIO (Empresas lucrativas) } \\
\hline \multicolumn{1}{|c|}{ Especificações } & $\mathbf{R} \mathbf{\$}$ & Média Ponderada \\
\hline RECEITA DE VENDAS & $\mathbf{2 . 8 8 1 . 8 6 2 , 0 0}$ & $100,0 \%$ \\
\hline (-) CUSTO DA MERCADORIA VENDIDA (CMV) & $\mathbf{9 4 4 . 9 2 0 , 0 0}$ & $32,8 \%$ \\
\hline (=) LUCRO BRUTO (Margem Bruta) & $\mathbf{1 . 9 3 6 . 9 4 2 , 0 0}$ & $67,2 \%$ \\
\hline (-) DESPESAS ADMINISTRATIVAS & $\mathbf{1 . 4 8 3 . 4 6 1 , 1 7}$ & $51,5 \%$ \\
\hline • Mão de obra & $692.519,73$ & $24,0 \%$ \\
\hline • Aluguel & $212.356,00$ & $7,4 \%$ \\
\hline • Tributos & $290.399,24$ & $10,1 \%$ \\
\hline • OUTRAS DESPESAS (Água, energia, telefone, etc.) & $288.186,20$ & $10,0 \%$ \\
\hline (=) RESULTADO LÍQUIDO (Margem Líquida de Lucro) & $\mathbf{4 5 3 . 4 8 0 , 8 3}$ & $15,7 \%$ \\
\hline
\end{tabular}

Fonte: Elaborado pelo autor. 
Quadro 8. DRE - Somatória dos valores das 6 empresas que apresentaram prejuízo.

\begin{tabular}{|l|c|c|}
\hline \multicolumn{2}{|c|}{ DEMONSTRAÇÃO DO RESULTADO DO EXERCÍCIO (Empresas com prejuízo) } \\
\hline \multicolumn{1}{|c|}{ Especificações } & $\mathbf{R} \$$ & Média Ponderada \\
\hline RECEITA DE VENDAS & $\mathbf{R} \mathbf{2 3 8 . 4 5 0 , 0 0}$ & $100,0 \%$ \\
\hline (-) CUSTO DA MERCADORIA VENDIDA (CMV) & $\mathbf{R} \mathbf{\$ 1 2 0 . 0 0 0 , 0 0}$ & $50,3 \%$ \\
\hline (=) LUCRO BRUTO (Margem Bruta de lucro) & $\mathbf{R} \mathbf{1 1 8 . 4 5 0 , 0 0}$ & $49,7 \%$ \\
\hline (-) DESPESAS ADMINISTRATIVAS & $\mathbf{R} \mathbf{1 5 7 . 3 1 1 , 6 5}$ & $66,0 \%$ \\
\hline • Mão de obra & $\mathrm{R} \$ 82.302,00$ & $34,5 \%$ \\
\hline • Ocupação & $\mathrm{R} \$ 36.500,00$ & $15,3 \%$ \\
\hline • Tributos & $\mathrm{R} \$ 14.664,65$ & $6,1 \%$ \\
\hline • OUTRAS DESPESAS (Água, energia, telefone, etc.) & $\mathrm{R} \$ 23.845,00$ & $10,0 \%$ \\
\hline (=) RESULTADO LÍQUUIDO (Margem Líquida de Lucro) & $\mathbf{- R ~} \mathbf{3 8 . 8 6 1 , 6 5}$ & $-16,3 \%$ \\
\hline
\end{tabular}

Fonte: Elaborado pelo autor.

Cabe destacar, conforme Quadro 8, os elevados custos dessas empresas especialmente com o CMV $(50,3 \%)$, com a mão de obra $(34,5 \%)$ e com a ocupação $(15,3 \%)$, todos muito acima da média do segmento. Há exceção para os tributos, tendo em vista que eles têm como base de cálculo as receitas de venda que são pequenas para essas 6 empresas. Embora representem 27,27\% das 22 empresas em estudo, suas vendas correspondem a apenas $7,6 \%$ do faturamento total.

\section{Considerações finais}

A pesquisa alcançou seu objetivo de analisar o resultado financeiro das empresas respondentes para servir como fonte de informação e auxiliar na elaboração de planejamento estratégico-financeiro das empresas do setor. No entanto, a análise foi feita considerando apenas 23 empresas das 126 que pertencem à ABRASEL. Assim, esta análise não poderá ser inferida para toda a população, ficando restrita às respondentes da pesquisa. Todavia, vale destacar sua relevância em virtude da inexistência de publicações de pesquisas a respeito deste tema e pela fundamental importância que as informações financeiras têm no sentido de servirem como referência para a elaboração do planejamento das empresas do setor.

Entre os resultados alcançados, destaca-se que seis empresas apresentaram prejuízo. Os motivos principais são: pequeno volume de vendas em relação às demais; menor margem de lucro bruto (que significa CMV elevado) e maioria dos custos fixos acima da média. Elas representam $27 \%$ das micro e pequenas empresas que responderam à pesquisa. Todas essas deficitárias são microempresas. Esse resultado corrobora com as pesquisas do SEBRAE (2011) que apontam o grande número de micro e pequenas empresas que fecham suas portas por problemas financeiros.

Outro destaque é a correlação negativa entre os percentuais dos custos fixos (especialmente os custos com mão de obra e ocupação do imóvel) e os resultados financeiros (lucro ou prejuízo). Assim, a administração deve ficar atenta à adequação dos níveis de venda em relação a esses dois custos fixos citados, além de buscar o aumento da margem bruta de lucro (relação entre lucro bruto e volume de vendas). Dessa forma, o alcance de um adequado volume de vendas em relação aos custos fixos é fundamental para que as empresas tenham resultados positivos.

Diante dessas considerações e dada a relevância do tema, recomenda-se que essa pesquisa seja realizada outras vezes para ampliar o número de respondentes de forma a consolidar seus resultados. Assim, ela poderá continuar contribuindo com as empresas do segmento que terão fundamentação para o planejamento financeiro e mais segurança para a permanência no mercado, gerando resultados positivos. Esta pesquisa poderá servir também como fonte de informações para a realização de planos de negócios para novos empreendimentos do setor.

\section{Referências}

Araujo, L. C. G. (2006). Gestão de pessoas: estratégias e integração organizacional. São Paulo: Atlas.

Assaf, A., No. (2012). Estrutura e análise de balanços - um enfoque econômico-financeiro. São Paulo: Atlas.

Associação Brasileira de Bares e Restaurantes - ABRASEL (2013). Perfil da Abrasel. Recuperado em 2 de janeiro de 2013, de http://www.abrasel.com.br

Associação Comercial e Industrial de Florianópolis - ACIF (2013). Florianópolis: dados econômicos. Recuperado em 9 de julho de 2013, de http://www.acif.org.br/ dados-economicos

Blanck, H. M., Yaroch, A. L., Atienza, A. A., Yi, S. L., Zhang, J., \& Mâsse, L. C. (2007). Factors influencing lunchtime food choices among working Americans. Health Education \& Behavior, 36(2), 289-301. PMid:17602103

Braga, R. M. M. (2008). Gestão da gastronomia. São Paulo: Editora Senac. 
Brasil. Ministério da Fazenda. Receita Federal (2013). Carga tributária no Brasil - 2011. Recuperado em 3 de julho de 2013, de http://www.receita.fazenda.gov. br/Publico/estudoTributarios/estatisticas/CTB2011.pdf

Cardoso, J. F. (2011). Custos e preço de venda: um estudo em restaurantes à la carte. Revista Hospitalidade, 8(2), 103-120.

Chiavenato, I. (2005). Gestão de pessoas (2 ed.). Rio de Janeiro: Elsevier.

Ferreira, L. F. F., Oliva, F. L., Santos, S. A., Grisi, C. C. H., \& Lima, A. C. (2012). Análise quantitativa sobre a mortalidade precoce de micro e pequenas empresas da cidade de São Paulo. Gestão \& Produção, 19(4), 811-823. http://dx.doi.org/10.1590/S0104-530X2012000400011.

Fonseca, M. T. (2009). Tecnologias gerenciais de restaurantes. São Paulo: Editora Senac.

Helfert, E. A. (2000). Técnicas de análise financeira: um guia prático para medir o desempenho dos negócios. Porto Alegre: Bookman.

Instituto Brasileiro de Geografia e Estatística - IBGE (2013). Produto interno bruto dos municípios - 2010. Recuperado em 25 de junho de 2013, de http://www.ibge.gov.br/ cidadesat/xtras/temas.php? codmun $=420540 \& i d t e m a=103$
Knight, J. B. (2005). Gestão, planejamento e operação de restaurantes. São Paulo: Roca.

Lapponi, J. C. (2000). Estatística usando excel 5 e 7. Rio de Janeiro: Campus.

Martins, E. (2006). Contabilidade de custos. São Paulo: Atlas.

Maximiano, A. C. A. (2008). Fundamentos da administração. São Paulo: Atlas.

Megliorini, E. (2007). Custos, análise e gestão. São Paulo: Pearson Prentice Hall.

Rebello, A. (2013). Sem CPMF e com crise a carga tributária subiu. Recuperado em 3 de julho de 2013, de http://www. administradores.com.br/artigos/economia-e-financas/ sem-cpmf-e-com-crise-a-carga-tributaria-subiu/31824/

Santos, M. V., Proença, R. P. C., Fiates, G. M. R., \& Calvo, F. M. C. (2011). Os restaurantes por peso no contexto de alimentação saudável fora de casa. Revista de Nutrição, 24(4), 641-649.

Serviço Brasileiro de Apoio às Micro e Pequenas Empresas - SEBRAE (2011). Sobrevivência das empresas no Brasil. Recuperado em 20 de junho de 2013, de http:// www.sebrae.com.br

Zanella, L. C. (2007). Instalação e administração de restaurantes. São Paulo: Metha. 
Apêndice 1. Questionário da pesquisa.

PESQUISA SOBRE O DESEMPENHO PARA O SEGMENTO DE ALIMENTAÇÃO FORA DO DOMICÍLIO

Esta pesquisa é uma iniciativa do Instituto Federal de Educação, Ciência e Tecnologia de Santa Catarina - IFSC em conjunto com a ABRASEL. O objetivo desta pesquisa é analisar o resultado financeiro das empresas do segmento de alimentação fora do domicílio e divulgar essa análise de forma que possa ser fonte de informação para auxiliar na elaboração de planejamento estratégico das empresas do setor. Os resultados serão divulgados junto à ABRASEL. Muito obrigado pela colaboração!

1) Quantidade de funcionários:

2) Tipo de serviço oferecido:

Somente à la carte (AL)

Somente self-service (por peso) (SP)

Diversos (à la carte, por peso, livre por pessoa) (DV)

3) Tipo do restaurante: (pode assinalar mais de uma opção)

Lanchonete/sanduicheria ( $\mathrm{LCH})$

Sanduicheria (SAN)

Restaurante de opções variadas (ROV)

Restaurante de especialidade (comida oriental, italiana, árabe, francesa, mexicana, churrascaria, internacional outros) (RES)

Outro. Qual?

4) Quais as modalidades de recebimento das vendas?
Cartão de crédito:
( )Não aceita
( )Aceita
( ) Aceita $\%$
Cartão de débito:
( )Não aceita
( ) Aceita _ \%
Ticket refeição:
( )Não aceita
( ) Aceita _ \%
Dinheiro:
( )Não aceita
( )Aceita $\%$

5) Qual o valor do tíquete médio? (Valor médio gasto por cliente)

6) Qual o valor médio gasto com matéria-prima por mês? (Alimentos e bebidas)

7) Qual o custo de ocupação?

Valor do aluguel (mesmo que seja próprio, qual seria o valor do aluguel do prédio) somado aos demais custos mensais relacionados à ocupação (condomínio, IPTU, etc.)

8) Qual o custo de mão de obra fora os encargos?

Valor da folha de pagamento (Média mensal)

9) Qual o percentual de rotatividade anual dos funcionários?

Como calcular: (Número de demissões + Número de admissões no ano) dividido por 2 e dividido pelo número de funcionários ativos.

10) Qual a quantidade média de clientes atendidos por mês? 


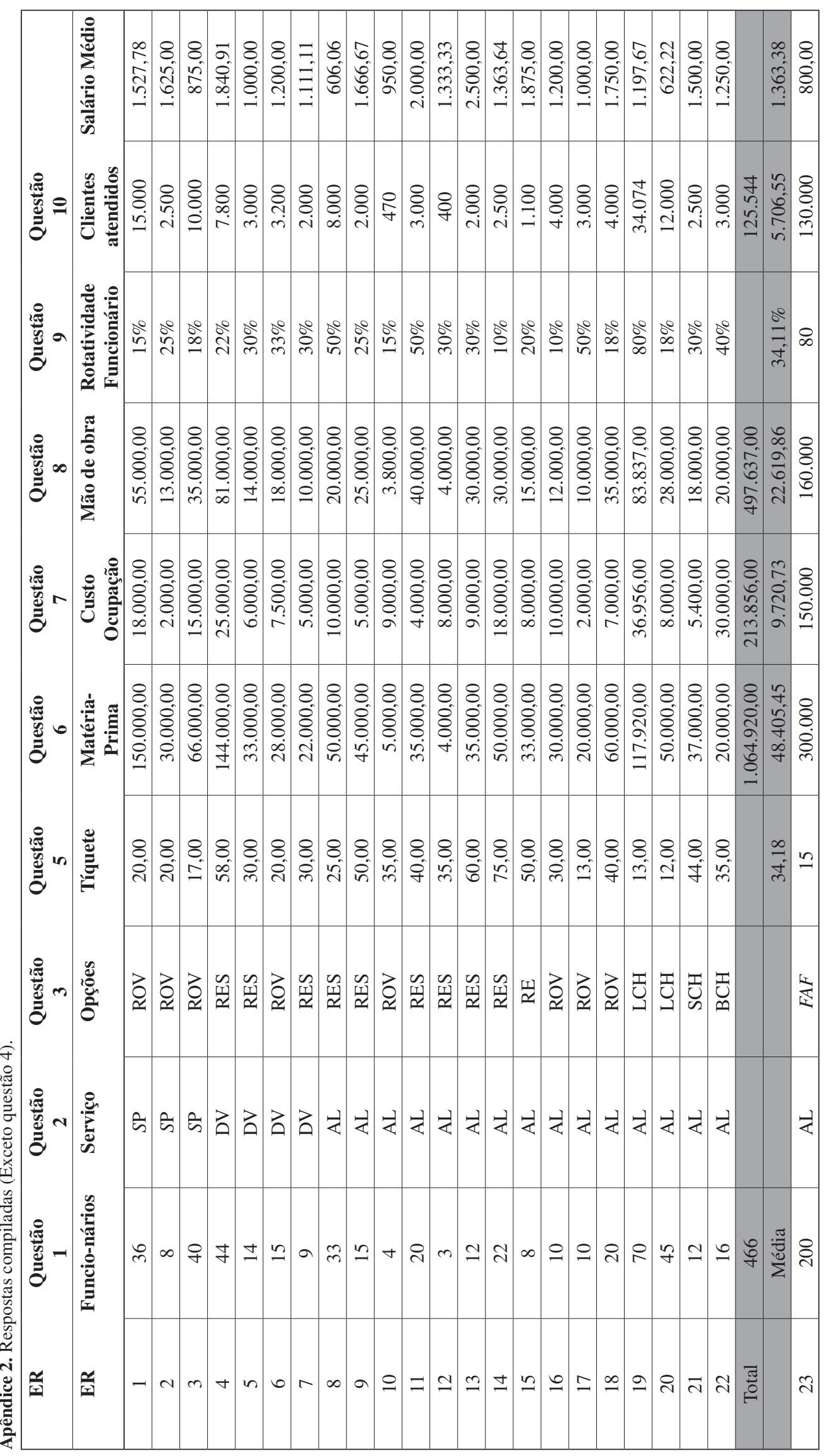




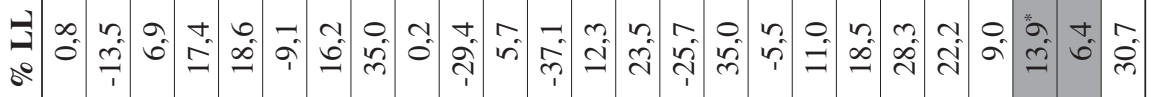

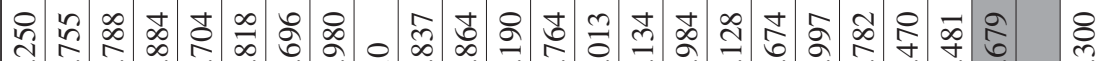

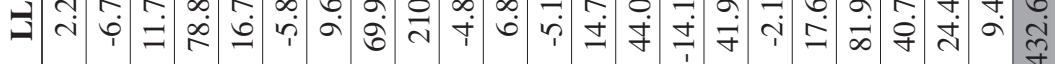

응ㅇㅇㅇㅇㅇㅇㅇㅇㅇㅇㅇㅇㅇㅇㅇㅇㅇㅇㅇㅇㅇㅇㅇㅇㅇㅇㅇㅡ

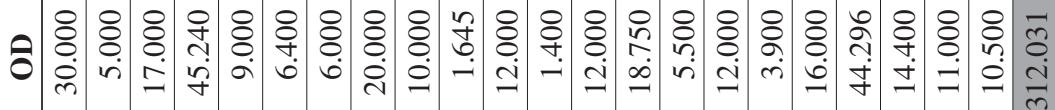

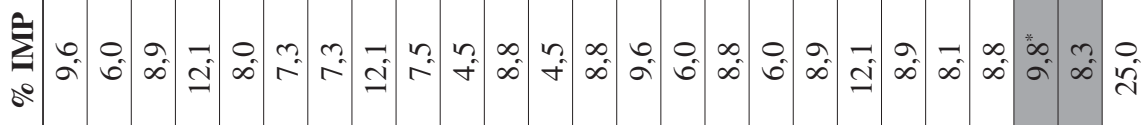

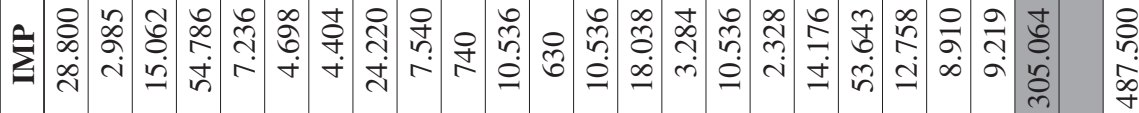

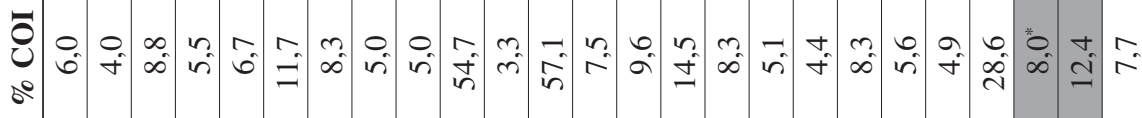

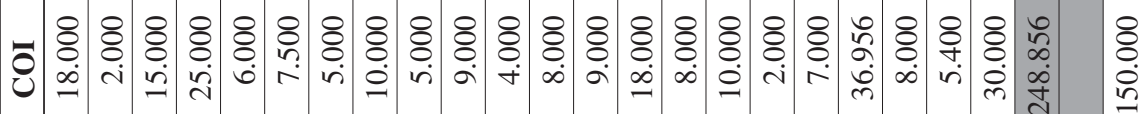

$\sum_{0}^{0}$ ले

se

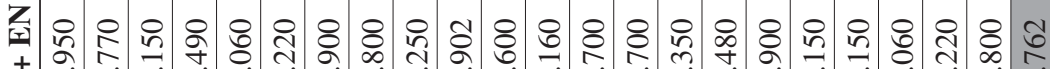

仓)

\begin{tabular}{l}
8 \\
8 \\
0 \\
\hdashline \\
$=$ \\
$=$
\end{tabular}

\& \& \& \& \& \& \&

जी

急

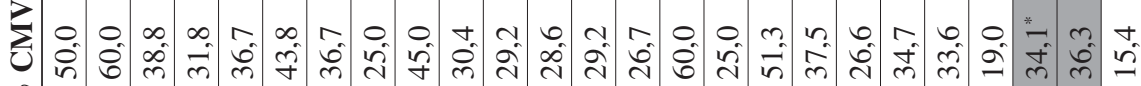
so

ఏ

U

ஓ.

క 